\title{
A Feira do Livro de Porto Alegre e a cultura sul-rio-grandense: identidades regionais no Caderno da Feira do Jornal $\mathbf{Z H}$
}

\author{
The Porto Alegre Book Fair and the culture of Rio Grande do Sul: regional \\ identities in the Journal's ZH Book Fair
}

\author{
Gisele Massola $^{1}$
}

\begin{abstract}
RESUMO
Nas perspectivas pós-estruturalistas considera-se que as identidades são produzidas por meio de práticas discursivas e que, por conta disso, não devem ser pensadas como uma questão de "ser", mas como um processo constante de "tornar-se" (WOODWARD, 2012). Focalizar tais identidades e problematizar instâncias e contextos histórico/culturais em que essas se estabelecem é uma das importantes tarefas a serem conduzidas, quando se pretende compreender como certas representações de sujeitos se tornam preponderantes em determinadas épocas e contextos. Neste artigo, que decorre de uma tese de doutorado concluída, destacam-se aspectos frequentemente associados à construção de identidades culturais gaúchas. Focaliza-se, centralmente, uma das muitas instâncias em que essas identidades se forjam - o encarte da Caderno da Feira, publicado pelo Jornal ZH no período de realização do prestigiado evento Feira do Livro de Porto Alegre que, está prestes a realizar septuagésimas edições ininterruptas. A partir de discussões conduzidas por Canclini (2007), Hall (1997; 2005; 2012), Woodward (2012), Silva (2012) entre outros, argumenta-se que as seções, artigos e notas informativas deste Caderno atuam na (re)construção de valores vinculados a identidades culturais gaúchas.
\end{abstract}

Palavras-chave: Estudos Culturais; Feira do Livro de Porto Alegre/RS; Identidade Cultural; Cultura Sul Riograndense; Gauchismo.

\begin{abstract}
In poststructuralist perspectives, identities are considered to be produced through discursive practices and that, because of this, they should not be thought of as a matter of "being", but as a constant process of "becoming" (WOODWARD , 2012). Focusing on such identities and problematizing historical/cultural instances and contexts in which they are established is one of the important tasks to be carried out, when trying to understand how certain representations of subjects become predominant in certain times and contexts. In this article, which stems from a completed doctoral thesis, aspects often associated with the construction of gaucho cultural identities are highlighted. It focuses, centrally, on one of the many instances in which these identities are forged - the insert of fair notebook, published by Jornal ZH during the period of the prestigious event Porto Alegre Book Fair, which is about to hold its seventieth uninterrupted editions. . Based on discussions conducted by Canclini (2007), Hall (1997; 2005; 2012), Woodward (2012), Silva (2012) among others, it is argued that the sections, articles and informative notes of this Notebook act in the (re) construction of values linked to gaucho cultural identities.
\end{abstract}

\footnotetext{
1 Universidade Luterana do Brasil (ULBRA)/Campus Canoas (RS)

*E-mail: giselemassola@gmail.com
} 
Keywords: Cultural Studies; Porto Alegre/RS Book Fair; Cultural Identity; South Riograndense Culture; Gauchism.

\section{INTRODUÇÃO}

Nas perspectivas pós-estruturalistas considera-se que as identidades são produzidas por meio de práticas discursivas e então, por conta disso, não devem ser pensadas como uma questão de "ser", mas como um processo constante de "tornar-se", conforme salientou Woodward (2012). Nesse sentido, ganha relevância a condução de estudos sobre processos de construção de identidades que envolvam, por exemplo, o exame de narrativas sobre certos acontecimentos e instâncias culturais, que se destacam em certos contextos em determinadas épocas, pois, usualmente, tais narrativas servem para dar coerência e coesão ao que acontece em processos que atuam na consolidação de certos mitos identitários.

A partir da perspectiva assumida no estudo aqui apresentado, os Estudos Culturais em sua intersecção com a Educação, entendendo serem as identidades forjadas, instituídas, ou engendradas em um conjunto de ações e processos, cabendo, portanto, aos investigadores que atuam neste campo, focalizar e problematizar tais processos. E essa é uma busca que tem sido procedida pelos praticantes do campo dos Estudos Culturais, cabendo lembrar que a vertente inglesa desses Estudos emergiu na década de 1960, no Centre for Contemporary Cultural Studies (CCCS) em Birmingham, Reino Unido. Cabe lembrar, ainda, que tal ${ }^{2}$ perspectiva teórica ganhou corpo em um panorama amplo de mudanças sociais e culturais processadas após o término da $2^{\mathrm{a}}$ Guerra Mundial, que se expressaram em formas de lidar com a cultura envolvendo, por exemplo, o rompimento com hierarquias, distinções e elitismos culturais, que implicavam segregacionismos e se pautavam no binarismo alta cultura $\mathrm{X}$ baixa cultura. Tais contestações, inicialmente mais vinculadas ao campo literário e ao da história da arte, reivindicavam a importância da realização de estudos sobre as chamadas culturas populares e midiáticas. Posteriormente, mobilizados pelo impacto de seu encontro com os posicionamentos feministas, bem como a partir de articulações procedidas com os estudos sobre semiótica e as teorizações pósestruturalistas, os praticantes de Estudos Culturais ampliaram o escopo de suas

\footnotetext{
2 Raymond Willians, Richard Hoggart, Stuart Hall, Angela McRobbie, Cary Nelson, Paula Treichler, Lawrence Grossberg, Norma Schulman e Carolina Escosteguy são alguns exemplos de estudiosos que já documentaram, em distintos momentos, aspectos da história dos Estudos Culturais.
} 
ponderações ao assumirem as viradas lingüística e cultural e ao reconhecerem o papel constitutivo das linguagens e das culturas sobre os sujeitos e suas compreensões de mundo.

Nos dias atuais, os praticantes desses Estudos persistem em seu propósito de transitar entre as fronteiras de diferentes saberes, mas, também, de evitar diferentes formas de reducionismo e de praticar contextualizações radicais (GROSSBERG, 2012), destacando a importância de se exercitarem articulações de diferentes ordens entre conceitos e saberes diversos.

Já no que diz respeito às inspirações que os estudos em educação têm buscado nos Estudos Culturais, cabe registrar a partir de Wortmann; Costa; Silveira (2015), que disso resultou a ampliação do que se entendia como educativo e pedagógico, não apenas por terem sido procedidas, neste encontro, ressignificações de entendimentos sobre a escola e o que nela sucede, mas também por ter-se assumido a ideia de que muitos e diferenciados artefatos e instâncias culturais operam como pedagogias potentes, tal como pretendo mostrar neste estudo, que resulta de uma investigação de doutorado em Educação. Com este propósito, focalizo, neste texto, um evento cultural importante para a cidade de Porto Alegre/RS, e para a cultura gaúcha, a Feira do Livro, prestes a realizar septuagésimas edições ininterruptas. Busco mostrar, valendo-nos de análises conduzidas sobre textos variados, colocados em circulação no Caderno da Feira do Jornal ZH, suplemento publicado no período de realização da Feira do Livro, ${ }^{3}$ estarem presentes, nas narrativas que focalizam este evento, representações que atuam na (re)construção de "modos de ver" a cultura gaúcha, bem como na definição de identidades culturais gaúchas.

Por certo, não são apenas as seções, as matérias de capa, as manchetes, as notas informativas contidas no referido Caderno, que atuam na definição de tais identidades. Entendo, valendo-me da noção de intertexto, tal como essa é apresentada por Fairclough

\footnotetext{
3 Este jornal integra o conjunto comunicacional da Rede Brasil Sul de Comunicação (RBS). Tal Grupo é apontado como um dos maiores complexos multimídia da Região Sul do país, possuindo, no Rio Grande do Sul e em Santa Catarina, oito jornais, 24 estações de rádio AM e FM, dois portais na internet, 17 emissoras de televisão afiliadas à Rede Globo, duas emissoras locais (denominadas comunitárias) e um canal veiculado nacionalmente voltado para o segmento rural. $\mathrm{O}$ jornal $\mathrm{ZH}$ é um dos oito jornais pertencentes ao Grupo RBS, sendo os demais: o Diário Gaúcho, o Pioneiro, o Diário de Santa Maria, o Diário Catarinense, o Jornal de Santa Catarina, a Hora de Santa Catarina e A Notícia. De acordo com informações divulgadas pelo Grupo RBS em seu site institucional, a tiragem do jornal já atingiu o número de 190 mil exemplares por dia.
} 
(1992), que reverberam nesses textos outras representações e outros discursos. Além disso, ressalto que esses textos se associam a outros, que integram processos que igualmente atuam na constituição de identidades. Ou seja, como nos ensinou o mesmo autor (ibid, p.134), “textos (...) são inerentemente intertextuais, constituídos por outros textos" e, ainda, como ele (ibid, p.135) ressalta, a partir de Kristeva (1986, p.39), a intertextualidade implica a inserção da história (sociedade) em um texto e deste texto da história". Enfim, como Fairclough (1992, p. 134) ressaltou, a inserção de um texto na história corresponde a este texto "responder, reacentuar e retrabalhar outros textos passados (...) antecipando e tentando moldar textos subseqüentes", sendo essa historicidade que permite a um texto desempenhar um papel central na sociedade relativamente a propiciar mudanças sociais e culturais (ibid, p.135).

A partir dessas colocações, ressalto a importância que a Feira do Livro alcançou no ambiente cultural gaúcho, pois este evento passou a ser vinculado a todo um conjunto de ações e iniciativas listadas como promotoras da cultura no Estado, que incluem financiamentos obtidos tanto a partir de órgãos públicos, quanto da iniciativa privada. $\mathrm{O}$ crescimento da importância deste evento suscitou meu interesse para a realização deste estudo, no qual busco discutir e problematizar configurações imprimidas à cultura sulriograndense.

Encontro em Canclini (2007) argumentos que nos auxiliaram a refletir sobre este evento. $\mathrm{O}$ autor (ibid) afirma que as problematizações sobre os usos e entendimentos do termo cultura, e do que tem sido considerado como cultural, têm-se voltado, cada vez mais, para compreensões dos processos de interação, confrontação e negociação procedidos em sistemas socioculturais diversos sob a ótica daqueles que produzem ou gestam a cultura. $\mathrm{O}$ autor (ibid) busca delinear perspectivas que, no tempo presente, estruturalmente marcado pela globalização, têm permitido a ocorrência de transformações de diferentes ordens - econômica, política, filosófica, científica, artística, tecnológica, social, cultural, etc.-, que vêm forjando algumas novas formas de viver e de pensar.

Como Canclini (ibid) salientou:

devemos considerar não só as definições múltiplas sobre o cultural dadas pelas ciências humanas e sociais, mas também as conceituações feitas pelos governos, mercados e movimentos sociais. As maneiras pelas quais se estão reorganizando a produção, a circulação e os consumos de bens culturais não 
são simples operações políticas ou mercantis; instauram modos novos de entender o que é cultural e quais são seus desempenhos sociais (CANCLINI, 2007, p. 49).

Para o autor, faz-se necessário ampliar o número de pesquisas que consideram os desafios lançados às políticas culturais na atualidade, atentando-se para a multiplicidade cultural dos centros urbanos das grandes cidades e para as redefinições do que se entende por cultura e para o papel a essa atribuído na sociedade. Somado a esses componentes, torna-se importante atentar, também, para os modos como têm acionando estratégias direcionadas ao consumo de imagens, mercadorias e eventos culturais, tal como sucede na Feira do Livro de Porto Alegre/RS.

\section{A FEIRA DO LIVRO DE PORTO ALEGRE/RS - UM IMPORTANTE EVENTO CULTURAL REGIONAL}

A Feira do Livro configura-se como um evento cultural múltiplo, que é realizado anual e ininterruptamente desde 1955, em Porto Alegre/RS, sob a chancela da Câmara Rio-Grandense do Livro (CRL), em parceria com a Prefeitura Municipal da cidade e com empresas estatais e privadas, as quais se valem de Leis de Incentivo à Cultura para patrociná-la.

O evento reúne atividades culturais de distintas ordens e mobiliza muitas práticas que têm caracterizado não apenas a Feira do Livro, mas, também, a própria cidade de Porto Alegre/RS e até mesmo os que participam do Evento. Cabe registrar que a Feira foi inspirada em evento semelhante realizado no local conhecido como Cinelândia, na cidade do Rio de Janeiro/RJ, seguindo sugestão feita pelo jornalista gaúcho Say Marques aos livreiros locais, no início dos anos cinqüenta. ${ }^{4}$

A intenção primeira da Feira - a popularização do livro - forneceu o mote para o slogan da $1^{\text {a }}$ edição do evento, realizado em novembro de 1955: "Se o povo não vem à livraria, vamos levar a livraria ao povo". Imbuídos dessa intenção, os promotores da Feira também almejavam a venda de livros e a ampliação do mercado literário.

Como grande parte das Feiras, essa também ocupa espaços públicos e, assim,

\footnotetext{
4 Marques foi diretor-secretário de um dos principais jornais do Rio Grande do Sul nos anos de 1950, o Diário de Notícias, fundado em 1925.
} 
desde a sua primeira edição, a Feira do Livro de Porto Alegre tem se realizado na Praça da Alfândega, que está localizada no chamado "Centro Histórico de Porto Alegre", passando, posteriormente, a ocupar prédios vizinhos localizados nas imediações, tendo inclusive se estendido, em algumas das suas edições (nos anos noventa, por exemplo) até a orla do lago Guaíba , onde ficam os armazéns do ${ }^{5}$ antigo Cais do Porto.

Entre os anos de 2005 e 2015, a Feira ocupou uma área de aproximadamente 24 mil metros quadrados de uma área central tombada pelo poder público municipal desde 1987 (DEROSSO; ORTIZ; SODRÉ, 2000), espalhando-se o evento, posteriormente, por diferentes espaços desse patrimônio histórico, ocupando ruas, salas do Memorial do Rio Grande do Sul, do Museu de Arte do Rio Grande do Sul, da Casa de Cultura Mário Quintana, do espaço Santander Cultural e dos Bancos Safra e Meridional, o antigo prédio do jornal Correio do Povo, o Museu de Comunicação Social Hipólito José da Costa, o Centro Cultural CEEE (Companhia Estadual de Energia Elétrica) Érico Veríssimo e os armazéns do Cais do Porto.

No ano de 2016, no entanto, houve uma redução em termos de proporções da estrutura arquitetônica e programações da Feira na Praça e seus entornos, em decorrência do impacto da redução de verbas dos programas federais destinados ao incentivo e fomento à cultura. Na edição $62^{\mathrm{a}}$ da Feira do Livro a ocupação total foi reduzida para pouco mais de 10 mil metros quadrados. Já as edições mais recentes, de 2020 e 2021, foram totalmente remodeladas para formatos virtuais adaptando-se às restrições de isolamento social orientadas por protocolos sanitários decorrentes da situação de Pandemia Covid-19.

Assim pela amplitude alcançada, a Feira do Livro chegou a ser apontada em jornais, bem como em informativos da Secretaria Municipal de Cultura de Porto Alegre (SMC) como um dos "maiores eventos culturais da América Latina realizados em espaços abertos". A Feira abrange programações dirigidas a públicos de diferentes faixas etárias, por aproximadamente 15 dias - o período compreendido entre a última sextafeira do mês de outubro e o segundo domingo do mês de novembro -, prolongando-se até a segunda ou terça-feira seguintes, quando o feriado nacional de 15 de novembro

\footnotetext{
${ }^{5}$ Este lago contorna a cidade numa extensão de cerca de $70 \mathrm{~km}$ de orla fluvial simbolizando e demarcando expressões geográficas bastante destacadas da paisagem da capital gaúcha. No seu entorno há um conjunto de ilhas, parques e de áreas de preservação natural representando um patrimônio socioambiental para a população local.
} 
(Proclamação da República) ocorre em um desses dias. Cabe referir, ainda, que, em 2005, a Feira foi integrada ao Patrimônio Histórico Cultural do Estado do Rio Grande do Sul, tendo recebido, em 2006, a Medalha do Mérito Cultural da Presidência da República. Além disso, desde 2010, este evento ganhou status de Patrimônio Imaterial de Porto Alegre, por iniciativa da Secretaria Municipal da Cultura de Porto Alegre, sendo reconhecimentos desta ordem que deixam marcada a sua importância para a cultura gaúcha e que nos permite pensar ser este evento um marcador cultural da cidade associado à divulgação e à comercialização de livros, ma também à construção de uma complexa rede de ações e práticas que reúne atividades culturais de distintas ordens. E entre essas estão tanto ações e práticas que consagram autores e produções culturais regionais, quanto as que se voltam à internacionalização do evento, através de convites de participação de editoras e escritores de outros países, tal como sucedeu, por exemplo, nos anos de 2011, 2012, 2013, 2014 e 2016, quando foram feitas especiais menções a países, respectivamente, como Portugal, México, Alemanha, Canadá e Cuba.

A partir da expansão bem como das articulações empreendidas com outras instâncias da sociedade gaúcha, a Feira do Livro pode ser considerada como um marco diferencial, bem como um atributo que qualifica a vida cultural da cidade de Porto Alegre/ RS.

Passo, a seguir, a adentrar na programação desta "Feira", ressaltando que em cada uma das suas edições, essa reúne em um mesmo local variadas programações culturais que também associam a comercialização dos livros (e das marcas que identificam os seus patrocinadores) ao entretenimento.

Durante a sua realização, nela transitam sujeitos diversos, entre esses escritores, livreiros, expositores, jornalistas, estudantes, professores, público visitante em geral, autoridades governamentais e políticas, profissionais ligados à produção e comercialização de livros, entre outros. Estão sediadas no espaço da Feira representações de editoras, de universidades, de instituições bancárias públicas e privadas, bem como da mídia - jornais, redes de televisão e rádios locais, que passam a produzir e a veicular algumas das suas programações diretamente da Feira.

Além disso, realizam-se na Feira mesas-redondas, palestras e debates sobre temas variados, registrando-se terem ocorrido ao longo de diferentes edições da Feira discussões sobre sustentabilidade, cinema e literatura, direitos autorais, patrimônio 
artístico, memória e preservação, perspectivas da economia brasileira frente à crise mundial, envelhecimento e longevidade, poesia, o papel da biblioteca e da leitura no desenvolvimento das sociedades, o papel do Plano Nacional do Livro e da Leitura (PNLL), políticas de leitura para estados e municípios, entre outros muitos temas. E, para discuti-los, em atividades abertas ao público em geral, comparecem à Feira autores, cartunistas, ilustradores, professores, representantes governamentais, jornalistas, psiquiatras, entre outros profissionais.

Ao lado de tudo isso, ocorrem apresentações musicais e de danças folclóricas, rodas de contação de histórias, saraus e oficinas literárias sobre poesia, crônica, linguagem de sinais, exibições de filmes, encenações de peças de teatro ${ }^{6}$ direcionandose, muitas delas, ao público infanto-juvenil. Também vale apontar para ${ }^{7}$ as atividades mais específicas, tais como a Hora do Educador (debates sobre temáticas variadas acessibilidade e inclusão, cultura popular, HQs - endereçados a professores), entre outros.

Em suma, a Feira acopla e reúne em seus espaços ações paralelas em que ocorrem eventos musicais, cênicos e educativos, além dos literários, o que a caracteriza como um complexo evento social, cultural, educacional e comercial. Ou seja, a Feira é um importante negócio cultural que inclui atividades econômicas organizadas de forma produtiva e lucrativa para promover a circulação e o consumo de produtos, que, em uma primeira instância são culturais, mesmo que nela se vendam e se promovam, também, serviços variados que lá se instalam aproveitando a afluência de público que essa propicia. E a Feira é, também, um espaço de visibilidade para anunciar, divulgar, promover e propagandear as marcas que identificam os seus diversos patrocinadores e apoiadores, entre os quais estão instituições bancárias públicas e privadas, redes de supermercados, grupos que atuam no setor de comunicação e indústrias, entre outros.

Cabe ressaltar que a amplitude dos espaços físicos que a Feira ocupa permite que

\footnotetext{
6 Os exemplos listados compuseram parte da programação da última edição realizada da Feira do Livro de Porto Alegre.

7 Para exemplificar, apresentamos dados divulgados ao final do evento pela Câmara Rio-Grandense do Livro (CRL) através do site institucional (http://www.camaradolivro.com.br). Na edição de 2015, o evento totalizou: 258 atividades na programação geral, entre encontros, oficinas, apresentações artísticas e seminários. Já na área infantil ocorreram 463 atividades desde encontros com autores e ilustradores, seminários, contações de histórias, apresentações de teatro, oficinas até exposições, entre outras. Cabe indicar ainda, a participação de cerca de 1,5 milhão pessoas na Praça, durante os dias de realização do evento.
} 
essa multiplicidade de atrações, atividades e exibições reúna um contingente diversificado e volumoso de públicos que são atraídos pela programação oferecida. Dessa forma, a Feira não promove apenas os livros, as livrarias e as editoras, mas toda uma ampla gama de produtos e produções de diferenciadas ordens.

Por fim, cabe indicar que a expansão deste evento não se restringe à sua dimensão física, mas, ainda, aos espaços que o apresentam na mídia, podendo-se atribuir também a isso o crescimento da participação do público neste evento. Além de a Feira ter espaços garantidos na mídia, de um modo geral, entre os quais está o Caderno da Feira, que analiso neste estudo, é relevante apontar que outro 'braço' do Jornal ZH - a RBS TV ocupa sistematicamente um espaço na Feira, realizando transmissões ao vivo, a partir de um estúdio nela localizado. Aliás, como já indicamos, muitas são as estações de rádio e de TV que mantêm um espaço de retransmissão a partir da Feira. Em razão desta notoriedade que o evento tem alcançado, arrisco-me a afirmar que essa se tornou um espetáculo, cujo projeto comporta ações de naturezas bastante diversas, havendo intervenções com propósitos mais pedagógicos que envolvem, inclusive, o público escolar. Valendo-me das considerações de Kellner $(2001 ; 2006)$ trago na esteira das análises empreendidas aqui o entendimento de espetáculo tomado como os modos de ser e viver podem ser compreendidos, nos dias de hoje, em grande parte condicionados pelos padrões e modelos fornecidos pela cultura da mídia pautando modelos cujos produtos são mercadorias criadas para atender aos interesses daqueles que produzem entretenimento. Para o autor (ibid) o entretenimento é o principal produto oferecido pela cultura da mídia, que espetaculariza o cotidiano de modo a seduzir suas audiências e levá-las a identificarse com as representações sociais e ideológicas nela presentes.

\section{SOBRE AS IDENTIDADES CULTURAIS QUE SE (RE)CONSTROEM NO CADERNO DA FEIRA}

A identidade integra o chamado circuito da cultura, expressão utilizada por ${ }^{8} \mathrm{Du}$

\footnotetext{
8 Tal expressão foi elaborada e utilizada por Paul Du Gay, Stuart Hall, Linda Janes, Hugh Mackay e Neith Negus (1997), fazendo referências a um estudo mais aprofundado acerca do artefato cultural Walkman da Sony, na tentativa de compreender seus modos de circulação e as relações simbólicas estabelecidas na cultura. Nessa concepção, configura-se um circuito de instâncias e mecanismos sociais que é composto por cinco processos correlacionados - sendo eles: (re)produção, consumo, identidade (e diferença), regulação e representação -, nos quais os efeitos e percepções de um artefato podem ser compreendidos. O circuito envolve os indivíduos numa rede de signos permanente e intensa. Dessa forma, o sujeito assimila os
} 
Gay e Hall (1997) para destacar o processo através do qual se produzem significados e no qual igualmente operam as representações, o consumo, os atos de regulação e produção. Conforme estes autores (ibid) indicam, representação e identidade relacionamse intimamente: as identidades vão sendo constituídas e vão também constituindo representações em processos em que se produzem hierarquizações e através dos quais definem-se quem os sujeitos são, como devem ser, como devem comportar-se, etc. As identidades, na compreensão de Hall (2012), Woodward (2012) e Silva (2012) são produzidas em processos sociais e em condições históricas específicas. Portanto, essas não se vinculam a nenhuma essência e não são imutáveis nem fixas. Nas palavras de Hall (2012) “elas são o resultado de uma bem-sucedida articulação ou fixação do sujeito ao fluxo discursivo" (p. 109) e as posições assumidas pelo autor afastam a compreensão das identidades de concepções essencialistas. Como o autor (ibid) explica:

\footnotetext{
Utilizo o termo identidade para significar o ponto de encontro, o ponto de sutura, entre, de um lado, os discursos e as práticas que tentam nos interpelar, nos falar ou nos convocar para que assumamos nossos lugares como sujeitos sociais de discursos particulares e, por outro lado, os processos que produzem subjetividades, que nos constroem como sujeitos, as posições de sujeito que as práticas discursivas constroem para nós (HALL, 2012, p. 111-112).
}

As identidades são produzidas nos discursos e como salientou Hall (2012), "precisamos compreendê-las como produzidas em locais históricos e institucionais específicos, no interior de formações e práticas discursivas específicas, por estratégias e iniciativas específicas" (p.109). E elas emergem, como salientou o mesmo autor (ibidem), "no interior do jogo de modalidades específicas de poder sendo, assim, mais o produto da marcação da diferença e da exclusão do que o signo de uma unidade idêntica, naturalmente constituída. É ainda importante acrescentar, como também nos ensinou Hall (ibid, p.112), que as "identidades são pontos de apego temporário às posições de sujeito que as práticas discursivas constroem para nós" (Hall, 1995, apud Hall, 2000) - as identidades “são o resultado de uma bem-sucedida articulação ou 'fixação' do sujeito ao fluxo discursivo (Hall, 2012, p.112). Cabe, no entanto, salientar, que os discursos e práticas a partir dos quais somos narrados e nos narramos (e também como somos posicionados e nos posicionamos) estão inscritos em relações assimétricas de poder.

Como Silva (2012) salientou, "quem tem o poder de representar tem o poder de definir e determinar a identidade" (p. 91). E é com base nessa identidade que se nomeia, 
que se posiciona a diferença, conferindo-lhe um lugar específico, inventando formas para representá-la e marcá-la por traços e/ou atributos que se consideram indesejáveis, ou destoantes, ou desviantes, ou anormais. Uma vez que as identidades não possuem sentidos fixos ou finais, há sempre poder e saber em exercício; há sempre uma luta em torno dos modos de representar.

$\mathrm{Na}$ investigação que realizei, interessou-me pensar sobre como nos jogos discursivos procedidos sobre a Feira do Livro de Porto Alegre/RS, que buscamos capturar, especialmente, a partir de reportagens do Caderno da Feira, que articulo a propagandas e a situações observadas no ambiente da praça, foram sendo construídas identidades que marcam a cultura sul-riograndense pela invocação a tradições, mitos, especificidades de gênero, entre outros aspectos que a distinguem de outras unidades da nação, e a localizam em uma posição de destaque.

\section{A FEIRA DO LIVRO E A CULTURA SUL-RIOGRANDENSE: IDENTIDADES CULTURAIS ACIONADAS NO ENCARTE CADERNO DA FEIRA}

O encarte Caderno da Feira, desde sua primeira edição, em 2005, tem sido o local eleito pelo jornal $\mathrm{ZH}$ para concentrar, publicizar e veicular notícias sobre a Feira do Livro. As reportagens que integram o Caderno trazem, usualmente, a programação e apontam para os principais destaques do dia. As outras matérias veiculadas contêm sugestões de obras a serem adquiridas, bem como entrevistas com autores que participam das sessões de autógrafos realizadas naquele dia, além de depoimentos colhidos junto ao público que acorre à Feira, fornecendo, ainda, 'dicas' de espaços a serem visitados, relação das bancas das editoras que oferecem livros em promoção e saldos e novidades e curiosidades sobre personalidades da literatura. Também é feita a cobertura da agenda diária do patrono e de suas ações, entre outros informativos referentes à programação e às atividades da Feira.

Desde a primeira versão, o Caderno vem mantendo, praticamente, o mesmo layout e projeto gráfico, estando dividido em três partes: capa, página central (organizada em duas folhas) e contracapa. A página de capa estampa, ao centro, o título do encarte e o logotipo da Feira. Logo abaixo está posicionada a manchete da reportagem central do dia, geralmente seguida de ilustrações, e da matéria em destaque. Observa-se, ainda, em colunas posicionadas ora no lado direito, ora no lado esquerdo da página, 
pequenas notas em formato de boxes, com frases mais curtas em negrito, informativos sobre entrevistas, autores, depoimentos, curiosidades e atrações destacadas a partir da reportagem principal. Já a página central dá destaque para a seção intitulada $O$ Patrono, na qual este faz indicações

diárias de obras de diferentes gêneros literários e científicos, que merecem ser lidas, e que ele apresenta em breves excertos, depoimentos, narrativas ou diálogos, bem como relatos do cotidiano do patrono nas dependências da Feira. Outras breves seções e matérias da autoria dos colunistas do jornal $\mathrm{ZH}$ ou de escritores locais, que falam de infância, adolescência, família, leitura, escola, política, personalidades, traumas, decepções, etc., opiniões, curiosidades, presença de autores, escritores, ilustradores e poetas, tanto nacionais quanto internacionais, literatura infantil, entre tantas outras matérias que permeiam a programação do evento, também estão nesta página central. $\mathrm{Na}$ contracapa está apresentada a programação do dia, sob formato de um convite para comparecer ao espaço da Praça ou para acessá-lo, a partir dos diferentes canais de comunicação do Grupo RBS, incluindo-se, entre esses, os ambientes virtuais.

Abro um parênteses para destacar que, no contexto cultural de Porto Alegre/RS, ser indicado para disputar o patronato da Feira do Livro implica ser elevado à categoria (e estar no rol ) de autor destacado no meio literário gaúcho, uma vez que essa escolha é definida a partir do voto de representantes de distintas instâncias culturais do Estado, entre as quais estão a Câmara Rio-Grandense do Livro (CRL), universidades públicas e privadas da região, além de patrocinadores vinculados a entidades culturais e sociais da sociedade civil. Ser escolhido patrono envolve, portanto, prestígio e distinção. Cabe ainda indicar que a figura do patrono tem sido alinhada à definição de identidades para a cultura sul-rio-grandense. O patrono tem projetada a sua identidade e a sua obra na Feira, em função das muitas ações que acontecem em torno dele. Ele ganha projeção no cenário literário, especialmente no cenário regional, e a sua obra passa a integrar o 'catálogo' das produções que representam a cultura sul-rio-grandense. Mas, para além disso, é possível dizer que a Feira como um todo representa alguns dos modos como o povo gaúcho lida com a cultura, que, no caso considerado, envolve dar especial atenção ao livro e à literatura, pois a esses é consagrado um evento anual que mobiliza tantos setores da sociedade sul-riograndense. 


\section{"GAÚCHO, GURI POETA, GAROTA PROPAGANDA E PROFESSOR/PESQUISADOR: MARCAS IDENTITÁRIAS REGIONAIS EM EVIDÊNCIA NA PRAÇA}

Nas edições de $2010\left(56^{\mathrm{a}}\right)$ e na de $2012\left(58^{\mathrm{a}}\right)$ da Feira, a figura do patrono se ajustou a uma imagem identitária sustentada pelo gauchismo. Na edição de 2010, o patrono foi um dos "ícones" do movimento tradicionalista no Rio Grande do Sul, o folclorista Paixão Côrtes. Já na segunda, o patrono foi Luiz Coronel, poeta, publicitário e compositor, também ligado aos movimentos tradicionalistas gaúchos. Ou seja, como estes dois patronos carregam,mesmo que com distintas proporções, fortes marcas de adesão ao movimento tradicionalista gaúcho, suas produções (poemas, canções, letras de músicas, sonetos, manuais...) são consideradas "verdadeiras" coletâneas dos valores, hábitos e costumes invocados para configurar as tradições regionalistas gaúchas. Essas são inclusive por vezes associadas à possibilidade de resgate das 'raízes' de uma cultura nativa (ou genuína) que teria sido esquecida. E isso se consubstancia no registro sempre destacado de terem eles nascido em cidades situadas na região do "pampa gaúcho".

No exemplar de 30/10/2010 do encarte Caderno da Feira, por exemplo, Paixão Côrtes foi apresentado como um agrônomo, folclorista, compositor, radialista e pesquisador da cultura brasileira, que se tornou um "ícone da cultura gaúcha”, tendo servido, inclusive, de modelo para a escultura que representa o "Laçador", erguida em 1958 na "entrada" da cidade de Porto Alegre, RS, que hoje é um dos cartões postais dessa cidade.

Na mesma matéria, estão referidas as obras escritas pelo patrono, entre as quais estão livros sobre a cultura gaúcha, entre eles: Gaúchos de faca na bota; Folclore Gaúcho: Festas, Bailes, Música e Religiosidade Rural; Aspectos da música e fonografia gaúcha; e $O$ Laçador, a história de um símbolo. Também está destacado nesta matéria, o trabalho de divulgação da cultura gaúcha por ele feito junto a escolas, a sua participação em piquetes e em outras atividades vinculadas aos Centros de Tradições Gaúchas (CTGs) . Na reportagem, Paixão Côrtes é e $^{9}$ presentado como "o responsável pelo renascimento

\footnotetext{
9 De acordo com Freitas (2007), o primeiro Centro de Tradições Gaúchas foi criado em 1948 e recebeu a denominação de CTG 35, em alusão ao ano de deflagração da Revolução Farroupilha, ocorrida no Rio Grande do Sul em 1835. Inicialmente, seus fundadores "pretendiam que o centro fosse uma agremiação de, no máximo, trinta e cinco participantes, mas depois foi decidido que ela estaria aberta para todos que dela quisessem participar" (p. 54-55). Entre os principais objetivos estavam: reunir-se para tomar chimarrão e
} 
do tradicionalismo, o idealizador da Chama Crioula, do Candeeiro Crioulo, da Ronda Crioula, e ${ }^{10}$ idealizador das comemorações da Semana Farroupilha, em 1947” (ZH, 30/10/2010). E, por tudo isso, ele é definido como um legítimo representante da cultura gaúcha tradicionalista - um sujeito ligado à vida campeira, que pesquisa e divulga manifestações artísticas gaúchas (dança, baile, bailanta, invernadas, saraus, declamações), que usa indumentárias caracterizadas como do 'gaúcho' (bombacha, lenço, chapéu, botas) e que assume hábitos alimentares definidos como peculiares à cultura gaúcha (comer churrasco e tomar chimarrão).

Em outras palavras, a reportagem retoma e enfatiza representações que associam o patrono da Feira a um estereotipado 'modelo' de homem regional - o gaúcho do campo - e eleva este patrono ao estatuto de símbolo dessa cultura gaúcha, ao destacar que nele estão marcadas as tradições historicamente invocadas para definir "quem são" os legítimos gaúchos. E, assim, nessa reportagem, narram-se e reinventam-se tradições e sujeitos que operam na (re)construção de uma história que confere ao gaúcho uma essência identitária unificada e vinculada a uma paisagem e a modos de vida peculiares o campo e a pecuária, por exemplo. Pode-se ainda considerar que nesta reportagem, bem como em outras publicadas no Caderno da Feira, ao longo dessa edição da Feira do Livro - Tradição na Praça (ZH, 30/10/2010); Os guris de Livramento (ZH, 30/10/2010); Meu RS: Paixão além do consagrado (ZH, 05/11/2010); Razões às pampas para ler (ZH, 09/11/2010) - dá-se legitimidade a um discurso que institui o gauchismo como o modo de vida característico dos habitantes do Rio Grande do Sul.

Já na reportagem apresentada na Figura 1, jogos semânticos e imagéticos articulam o folclore rio-grandense ao patrono e nela se complexificam os atributos acionados para compor a 'figura' do patrono. Na fotografia maior, ele está em destaque, vestido com um traje social e usando uma surpreendente boina colorida na cabeça, além

cultuar os hábitos do interior como, por exemplo, as charlas dos peões nos galpões das estâncias, a fim de recriar os costumes da região da Campanha e das estâncias, os quais os fundadores do movimento julgavam ser as "autênticas" tradições gaúchas. Desde então, muitos outros centros semelhantes a esse foram constituídos, incorporando-se ainda outras práticas, como: danças gauchescas, apresentações musicais nativistas, bailes, invernadas, culinária campeira, entre outras ações. Além disso, esses CTGs disseminaram-se tanto no Rio Grande do Sul quanto em vários outros estados do Brasil e também em outros países.

10 Vale referir que tanto a chama, o candeeiro quanto a ronda remetem-se a rituais introduzidos, ainda na década de 1947, entre os adeptos do tradicionalismo gaúcho para demarcar e simbolizar o início das festividades que culminam nos festejos alusivos à Semana Farroupilha. Através destas práticas - representam-se, respectivamente, a "alma" armazenada localmente sob a vigilância da "guarda de honra" tendo seu início no Palácio do Governador do RS sendo conduzida ao acampamento no Parque Farroupilha - são realizadas cerimônias oficiais buscando enaltecer simbologias e sentimentos de resgate aos ideais tradicionalistas. 
de ter nas mãos a matraca, instrumento que substituiu, nesta $56^{a}$ edição da Feira, as tradicionais badaladas de sineta, que usualmente marcam o início da Feira. Ao fundo, na mesma foto, estão grupos em trajes folclóricos: alguns gauchescos, como pilchas e vestidos de prenda, outros que remetem a manifestações folclóricas como o maçambique, ritual religioso afro-católico através do qual as comunidades negras prestam homenagens a santos de devoção católica negra. A reportagem marca a presença, na cerimônia de abertura da Feira no ano de 2010, de manifestações folclóricas de alguns diferentes grupos que compõem a ${ }^{11}$ população do Estado. E os títulos que apresentam as matérias que integram a reportagem reforçam que a 'Tradição está na praça', inscrita na matraca, na payada, nos grupos retratados na fotografia, e na figura do patrono - o 'paixão'. Porém, a essa 'tradição' está sendo incorporada à erudição do patrono - um reconhecido investigador/ reescritor da cultura sul-riograndense que objetiva "levar as tradições campeiras que pesquisou ao longo de seis décadas para a festa urbana da Feira" ( $Z H$, 30/10/2010, p. 34).

Figura 1 - Reportagem Tradição na Praça: matraca, payada e Paixão, que destaca a inserção do patrono da Feira do Livro de 2010, Paixão Côrtes, na cultura tradicionalista gaúcha

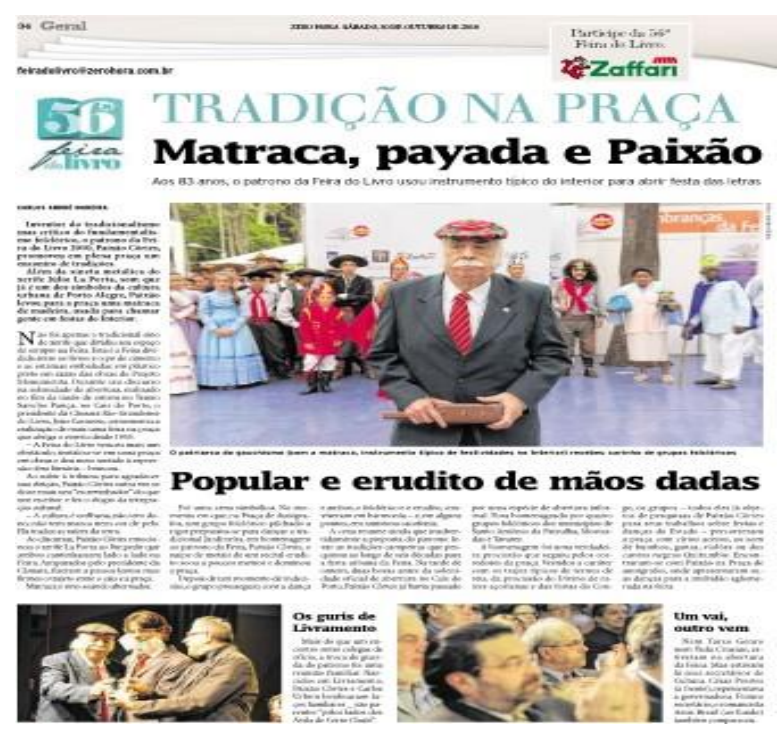

$(Z H, 30 / 10 / 2010$, p. 34)

\footnotetext{
${ }^{11}$ A matéria registra terem sido apresentados na ocasião grupos de invernadas das cidades de Tavares e Mostardas, situadas no litoral gaúcho, e a substituição das tradicionais badaladas de sineta, que marcam o início da Feira, pelo toque de uma matraca.
} 
E a reportagem relata, também, a cerimônia que deu início aos trabalhos da Feira: o hino sul-rio-grandense, a caminhada pelas alamedas até a Praça de Autógrafos e as apresentações de danças gauchescas, realizadas por dois Centros de Tradições Gaúchas (CTGs). Além disso, o comentário de uma visitante da Feira transcrito na reportagem "Olha, filho, aquele ali é o Laçador" - novamente posiciona o patrono como símbolo do gauchismo.

E a associação do patrono a símbolos que representam o gauchismo estão também presentes na reportagem que narra o encerramento da Feira de 2010 ( $Z H, 13 / 11 / 2010)$. O título dessa reportagem salienta ter Paixão Côrtes utilizado uma "guaiaca cheia de histórias" para ministrar uma aula de cultura sobre o mate e a simbologia do chimarrão a participantes da Feira. CTG . A matéria transcreve ${ }^{12}$ explicações dadas pelo patrono: "mate é a erva (...) e a palavra chimarrão vem do espanhol cimarrón, que significa selvagem, daí o significado etimológico da palavra ser 'bebida selvagem"”. E ele acrescentou ainda outros significados associados a essa tradição: oferecer "mate com mel significa 'quero casar contigo', já mate com água quente servida pela bomba quer dizer 'desapareça da minha frente!'”.

Figura 2 - Matéria Na Praça com o Patrono, que destaca a última atividade da Feira do Livro de 2010

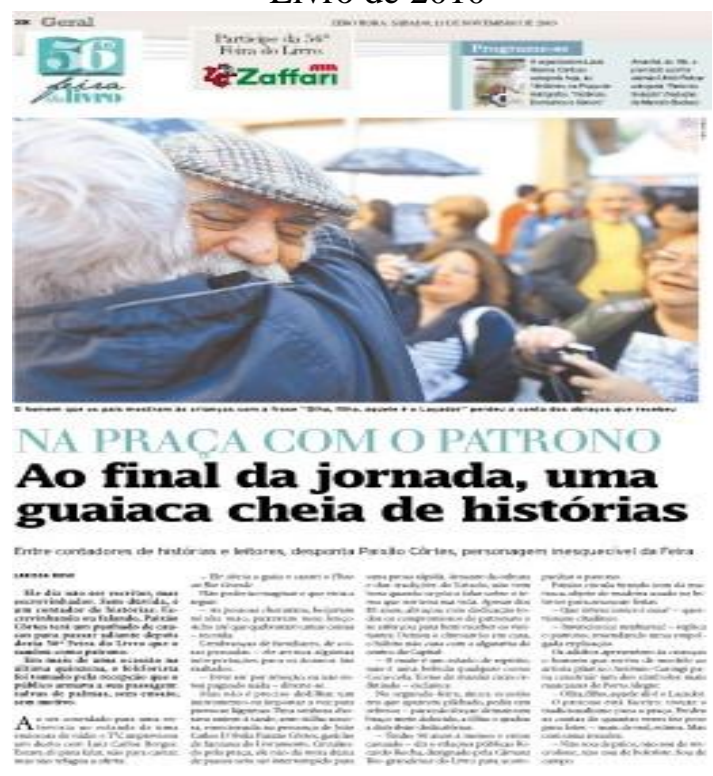

(ZH, 13/11/2010, p. 28)

\footnotetext{
12 Está mencionado na matéria o CTG Brazão do Rio Grande.
} 
Como se pôde ver são destacadas, nas duas matérias jornalísticas comentadas, expressões, hábitos e práticas que integram as tradições culturais sul-riograndense, aspectos também salientados em reportagens que apresentaram o patrono escolhido para o ano de 2012, o poeta Luiz Coronel.

Usualmente Coronel não usa uma pilcha e para registrar à sua identidade gaúcha está enfatizada na reportagem tanto a sua ‘origem' campeira - ele nasceu na cidade de Bagé RS na campanha gaúcha - e a constância dos temas ${ }^{13}$ gauchescos em sua vasta obra - 52 livros, com destaque para a poesia universal e regional.

Na matéria reproduzida na Figura 3, publicada no Caderno da Feira em 30/10/2012, o destaque foi a sessão de autógrafos da sua mais recente obra de poesias do autor, nomeada A Esperança e o Desalento: Poesia Sócia. A matéria enfatiza a produtividade literária do patrono, advogado e sociólogo de formação e Membro da Academia Rio-Grandense de Letras.

Figura 3 - Matéria incluída na seção Dia do Patrono, do encarte Caderno da Feira, com indicações de leituras pelo patrono, Luiz Coronel

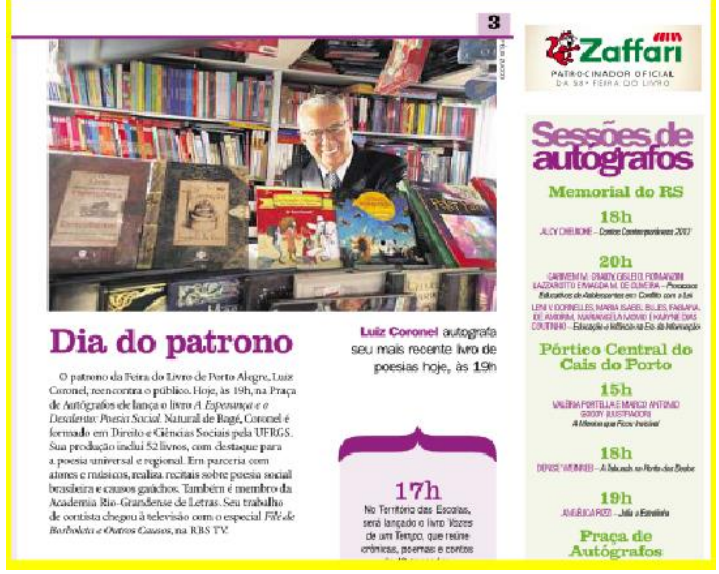

(ZH, 30/10/2012, p. 3)

Mas outras matérias publicadas no Caderno da Feira também valorizaram a identidade gaúcha do patrono, estando entre essas as reportagens intituladas: Um escritor

\footnotetext{
${ }^{13}$ Nesta matéria Coronel foi apresentado como "natural de Bagé", formado em Direito e Ciências Sociais pela UFRGS e Membro da Academia Rio-Grandense de Letras.
} 
quase gaúcho $(Z H, 30 / 10 / 2012)$, na qual indica suas crônicas e livros de prosa com causos de boliche e de galpão, O escritor da Fronteira e o Poeta da cidade (ZH, 31/10/2012, p. 3), na qual trata da temática da terra, no que retoma a tradição do cancioneiro sul-riograndense, Literatura do Cone Sul (ZH, 2/11/2012, p. 2), na qual fala de personagens que fizeram história aqui no Rio Grande do Sul, Açorianos na Feira (ZH, 2/11/2012, p. 4), na qual descreve personalidades históricas, imigrantes, cantores, entre outros tópicos voltados ao âmbito regional, Dia do Rio Grande do Sul e de Simões Lopes Neto (ZH, 5/11/2012, p. 2), Gauchada (ZH, 06/11/2012), sobre aspectos históricos da Guerra dos Farrapos, Até onde vai esse Guri? (ZH, 9/11/2012, p. 2), na qual relata episódios da infância, da juventude e de sua vida no interior do Estado.

É possível dizer que praticamente todas as manchetes, crônicas e reportagens destacadas pelo "Caderno" durante esta edição $\left(58^{\mathrm{a}}\right)$ da Feira trataram de personalidades ou de produções literárias de escritores do Rio Grande do Sul. Argumento que em tais reportagens constroem-se formas de pensar sobre a cultura sul-rio-grandense expressadas, muitas vezes, sob a forma de um gauchismo ou de uma gauchidade, neologismo referido por Silveira (2000) para referir características e "qualidades" associadas a um presumido e bem peculiar modo de ser gaúcho, que ressaltam, por exemplo, a sua “origem"/raiz campeira. Porém justifico, também, que as invenções identitárias procedidas no Caderno da Feira e no conjunto de ações executadas ao longo do evento Feira do Livro, não apenas tendem a marcar os sujeitos sul-rio-grandenses a partir dessa tradição, mas contemplam, por vezes, a adesão a identidades mais urbanas ou abrem espaços para identidades de gênero.

Na edição de 2011 foi eleita uma patrona para a Feira - a professora universitária Jane Tutikian - professora de literatura, e autora de inúmeros textos e livros que circulam no cenário cultural gaúcho, centrando-se suas produções em temas tais como: estudos literários, culturais e linguísticos concernentes às áreas lusofônicas não-brasileiras, identidade e história. Aliás Tutikian foi uma das poucas mulheres que receberam o título de patrona da Feira do Livro, tendo sido ${ }^{14}$ introduzidos nesta edição $\left(57^{\mathrm{a}}\right)$ da Feira os chamados dias temáticos, nos quais temas relativos à raça, etnia, gênero, sexualidade,

\footnotetext{
${ }^{14}$ Em edições anteriores ao patronato de Jane Tutikian foram indicadas: Lya Luft (1996) e Patrícia Bins (1998). Já em edições posteriores destaca-se: Cíntia Moscovich (2016), Valesca de Assis (2017), Maria Carpi (2018) e Marô Barbieri (2019) totalizando somente sete mulheres se comparado ao "universo" de mais de cinquenta homens homenageados com o título de patrono da Feira do Livro de Porto Alegre/RS.
} 
deficiência, cultura e religião eram focalizados. A seguir, examino reportagens que salientaram a presença e a participação da patrona no evento.

Em matéria publicada no dia 13/11/2011 foram salientados os 30 anos de carreira literária de Tutikian, que foi, também, diretora do Instituto de Letras da Universidade Federal do Rio Grande do Sul (UFRGS), sendo autora de mais de dezesseis obras - oito delas de literatura infanto-juvenil - que, como o texto da matéria ressaltou, "surpreendem pela originalidade de estilo, pela delicadeza, por sua vocação para valorizar o senso de humanidade, com tratamento delicado e elegante da patrona" (ZH, 13/11/2011).

Cabe comentar sobre os adjetivos empregados no mesmo artigo para qualificar a sua obra literária, pois esses evocam atributos usualmente usados histórica social e culturalmente para marcar o feminino, estando entre estes a afetuosidade, a doçura, a afetividade, a discrição e a fragilidade. Lembramos que as identidades são forjadas em práticas culturais específicas, sendo essas sempre transitórias, múltiplas e instituídas a partir de relações de poder/saber procedidas em práticas representacionais. As representações de gênero como indicou Scott (1995, p. 75) são construções culturais que posicionam os sujeitos a partir de papéis que lhes são atribuídos nas sociedades, decorrendo disso a atribuição de peculiaridade ao ser homem, mulher, jovem, idoso, gaúcho, metropolitano, etc.

Assim, pode-se dizer que ao invocar tais atributos a literatura da patrona está sendo definida como 'feminina', tal como em artigos anteriores a literatura de Paixão Côrtes e Luiz Coronel era qualificada como regional. Ou seja, a marca da 'gauchidade' não está explicitamente atribuída à patrona nas matérias publicadas no Caderno da Feira, mas ela foi marcada como "a mulher que simboliza a Praça" (Caderno da Feira, 15/11/2011) e como a "Garota-propaganda" da Feira do Livro, como está registrado na reportagem publicada no caderno nesta mesma data, ao lado de uma imagem (Figura 4), que fortalece esta afirmação, ao mostrar a patrona sorridente cumprimentando os visitantes dos estandes. Em relação a esta $\left(57^{\mathrm{a}}\right)$ edição da Feira é possível dizer que a participação do feminino em muitas instâncias da esfera pública, bem como registros da atuação das mulheres no cenário literário local e internacional ocupou espaços importantes nas matérias publicadas no Caderno da Feira, no ano de 2011. Tais reportagens registraram as presenças no evento das escritoras gaúchas Lya Luft, Cíntia Moscovich, Claudia Tajes e Marta Medeiros; da paulistana Patrícia Melo; da carioca 
Mari Del Priore e das convidadas internacionais, a portuguesa Lídia Jorge e a ítalobrasileira Marina Colasanti, bem como da então Ministra da Cultura, Ana de Hollanda, que representou a então presidente do Brasil, Dilma Roussef, no ato de abertura da Feira.

Enfim, esta edição da Feira deu especial atenção à presença feminina, sendo importante ressaltar que a presença de Tutikian na relação de patronos da Feira deixou uma marca indelével do feminino na história da Feira, mesmo que tal marcação se hibridize e se altere a partir de discursos em circulação em outras instâncias e produções da cultura.

Figura 4 - Matéria Garota-propaganda, que destaca o papel da patrona Jane Tutikian na Feira do Livro de 2011
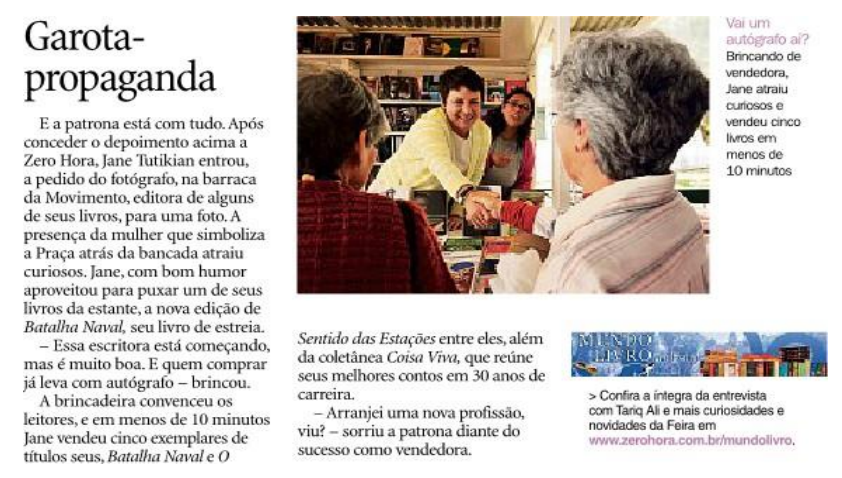

$(Z H, 15 / 11 / 2011$, p. 23$)$

Cabe ainda referir que o slogan que marcou todos os materiais de divulgação desta Feira do Livro - Cada um vem por um motivo. Descubra o seu. Descubra a sua feira - destaca a multiplicidade de aspectos implicados neste evento cultural, tal como já indicamos anteriormente. O Caderno veiculou reportagens sobre a Feira posicionando-a como um evento cultural amplo e diversificado, que necessita ter seus meandros explorados e suas possibilidades rastreadas para que cada um dos visitantes nela encontre aquilo que efetivamente lhe interessa $(Z H, 2 / 11 / 2011)$.

Comento, a seguir, como a figura de um outro patrono - o professor Luís Augusto Fischer - patrono da Feira na $59^{a}$ edição, realizada em 2013, integra o processo de construção de uma identidade para a Feira e para cultura sul-riograndense. Em muitas matérias publicadas nos Cadernos de 2013 foram feitas indicações sobre obras e de escritores gaúchos falecidos, dando visibilidade às suas produções. Registro que foi nesta edição da Feira que o Caderno passou a recomendar obras literárias, a partir de seleção feita pelo patrono em uma coluna diária, nomeada $O$ patrono indica. Constavam dessa coluna comentários do patrono, trechos extraídos das versões originais das obras 
comentadas, bem como descrições dos seus personagens centrais, por vezes ilustradas de forma caricata. Dessa forma, como o patrono assinalou em seus comentários, ele intencionava destacar e dar visibilidade a escritores que, segundo ele, têm importância histórica, mas cuja expressão intelectual ficou, por vezes, obscurecida. Entre os que figuraram em seus comentários estão os poetas Oliveira Silveira e Aparício Silva Rillo $(Z H, 3 / 11 / 2013)$ e a literatura de suspense, terror que contou com o seu incentivo para a realização de oficinas literárias.

De certa forma é possível perceber, entre as seleções referidas por Fischer na matéria uma maior ênfase a nuances que vão além da retrospectiva de obras e autores que marcaram a literatura brasileira. $\mathrm{O}$ autor se debruça sobre a forma como a trajetória literária do país tem sido pensada e contada. Abraçando a complexidade de seu objetivo — propor uma forma diferente de contar a história da literatura brasileira —, Fischer traça um panorama abrangente do caminho percorrido até aqui e deixa suas reflexões como rica contribuição para a construção conjunta dessa narrativa. Talvez a marca identitária mais presente nas descrições feitas deste patrono digam respeito ao seu papel de professor/pesquisador do campo da literatura - um acadêmico estudioso da literatura brasileira e que participa ativamente da vida cultural da cidade de Porto Alegre/RS.

Figura 5 - Reprodução da portagem Coletânea de perfis pelo patrono, com destaque para indicações do patrono da Feira do Livro de 2013,

Luís Augusto Fischer

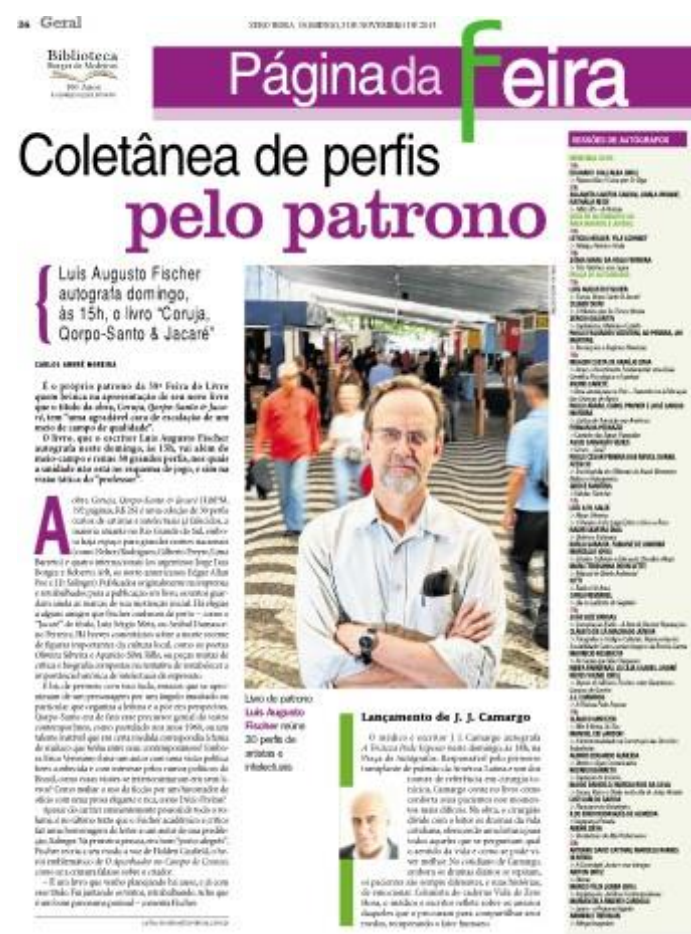

(ZH, 3/11/2013, p. 26) 


\section{ALGUMAS PALAVRAS FINAIS}

Por tudo que foi apresentado até aqui, afirmo, mais uma vez, que a Feira do Livro é muito mais do que um espaço de comercialização de livros; ela é um evento cultural múltiplo que vem caracterizando a cultura regional sul-rio-grandense. Realizada em um espaço público a céu aberto, ela oportuniza aos públicos e demais participantes da Feira experiências intelectuais, lúdicas, estéticas, comerciais etc.

O Caderno da Feira, por sua vez, é um encarte que surgiu na $51^{\text {a }}$ edição deste evento, no ano de 2005, a partir da ampliação da importância que o mesmo alcançou ao longo dos quase que últimos vinte anos. A função principal do Caderno é falar da Feira - divulgar tudo o que nela ocorre, bem como dar destaque a seus patrocinadores. Ao fazer isso, pode-se dizer que o Caderno é uma das instâncias que (re)inventa a Feira e que sobre ela ensina aos seus/suas leitores/as sobre o que vale a pena ser visto, lido, comprado, apreciado e até mesmo saboreado nos múltiplos espaços que a Feira oferece nos cerca de 15 dias em que essa ocorre. Nele se ensina, também, sobre os patronos, através da marcação de características que os posicionam dentro do contexto cultural sulriograndense. Escritores marcados pelo regionalismo, mulheres escritoras, professores/as de literatura, jornalistas têm ocupado o papel de patronos/as da Feira. Argumento que nas significações associadas a estes/as patronos/as são imprimidas marcas, não apenas para as obras que eles/elas escrevem, mas também construídas representações sobre a produção literária sul-riograndense. Enfim, o evento Feira do Livro representa a cultura sul-riograndense, mas não de uma forma uniforme, como foi possível ver neste texto. E neste processo são marcadas, neste evento, e a partir dele, algumas identidades como 'mais gaúchas', 'mais femininas', 'mais cosmopolitas', 'mais locais', 'mais comerciais', 'mais lúdicas', 'mais acadêmicas' em meio a patrocínios que localizam empresas regionais como 'mais atentas' e vinculadas ao desenvolvimento cultural sulriograndense.

\section{REFERÊNCIAS}

CANCLINI, Néstor Garcia. Diferentes, desiguais e desconectados. Rio de Janeiro: Ed. UFRJ, 2007.

DEROSSO, Simone; ORTIZ, Hellen; SODRÉ, Elaine (Orgs). Os Bastidores da Feira do Livro. Porto Alegre: Secretaria Municipal da Cultura, 2000. 
FAIRCLOUGH, Norman. Discourse and social change. Oxford and Cambridge: Polity Press and Blackwell, 1992.

FREITAS, Letícia Fonseca. A sala de aula como um espaço que constitui a identidade gaúcha. Educação \& Realidade. Porto Alegre, v. 32, nº 2, jul./dez. 2007.

GROSSBERG, Lawrence. Existe Lugar Para os Intelectuais no Novo Radicalismo? Três paradigmas. In: SARAIVA, Karla; MARCELLO, Fabiana de Amorim (Org.). Estudos culturais e educação: desafios atuais. Canoas: Ed. ULBRA, 2012.

HALL, Stuart. Quem precisa de identidade? SILVA, Tomaz Tadeu; HALL, Stuart; WOODWARD, Kathryn. (Org.) Identidade e diferença: a perspectiva dos Estudos Culturais. 11 a Ed. Petrópolis, RJ: Vozes, 2012.

Stuart. A identidade cultural na pós-modernidade. $10^{\mathrm{a}}$ Ed. Rio de Janeiro: DP\&A, 2005.

A centralidade da cultura: notas sobre as revoluções de nosso tempo. Educação \& Realidade. Porto Alegre, v.22, nº. 2, jul./dez. 1997.

KELLNER, Douglas. A cultura da mídia. Bauru, SP: EDUSC, 2001.

. "Cultura da mídia e triunfo do espetáculo" Em: MORAES, Dênis de (org.). Sociedade midiatizada. Rio de Janeiro: Mauad, 2006.

KRISTEVA, Julia. About Chinese Women. In: MOI, Toril (Org.). The Kristeva Reader. Oxford: Blackwell Publishers, p. 138-159, 1986.

LOURO, Guacira Lopes. Gênero, sexualidade e educação: uma perspectiva pósestruturalista. 9ª ed., Petrópolis, RJ: Editora Vozes, 2007.

NELSON, Cary; TREICHLER, Paula; GROSSBERG, Lawrence. Estudos Culturais; uma introdução. In: SILVA, Tomaz Tadeu. Alienígenas na sala de aula: uma introdução aos estudos culturais em educação. $6^{a}$ Ed. Petrópolis/RJ: Editora Vozes, 1995.

SCOTT, Joan. Gênero: uma categoria útil de análise histórica. Educação \& Realidade, no 20, vol. 2, jul/dez, 1995.

SILVA, Tomaz Tadeu. A produção social da identidade e da diferença. In: SILVA, Tomaz Tadeu; HALL, Stuart; WOODWARD, Kathryn. (Org.) Identidade e diferença: a perspectiva dos Estudos Culturais. 11 ${ }^{\mathrm{a}}$ Ed. Petrópolis, RJ: Vozes, 2012.

SILVEIRA, Rosa Hessel. "Ser gaúcho/a", escola e Vinte de Setembro. In: AZEVEDO, José Clóvis; GENTILI, Pablo; KRUG, Andréa; SIMON, Cátia (Org.). Utopia e Democracia na Escola Cidadã. Porto Alegre: Editora da UFRGS, 2000.

WOODWARD, Kathryn. Identidade e diferença: uma introdução teórica conceitual. In: SILVA, Tomaz Tadeu; HALL, Stuart; WOODWARD, Kathryn. (Org.) Identidade e diferença: a perspectiva dos Estudos Culturais. 11ª Ed. Petrópolis, RJ: Vozes, 2012.

WORTMANN, Maria Lúcia; COSTA, Marisa; SILVEIRA, Rosa. Sobre a Emergência e a Expansão dos Estudos Culturais em Educação no Brasil. Educação, Porto Alegre, v. 38, n. 1, p. 32-48, jan./abr. 2015.

\section{Exemplares Analisados do Caderno da Feira}

Jornal $Z H$, ano 46, $\mathrm{n}^{\circ} 16493$, de 30 de outubro de 2010. 
Jornal $Z H$, ano 46, $\mathrm{n}^{\circ} 16499$, de 05 de novembro de 2010. Jornal $Z H$, ano 46, $\mathrm{n}^{\circ} 16503$, de 09 de novembro de 2010 . Jornal $Z H$, ano 47, $\mathrm{n}^{\circ} 16829$, de 02 de novembro de 2011. Jornal $Z H$, ano $47, \mathrm{n}^{\circ} 16840$, de 13 de novembro de 2011. Jornal $Z H$, ano 47, $\mathrm{n}^{\circ} 16842$, de 15 de novembro de 2011. Jornal $Z H$, ano 48, $\mathrm{n}^{\circ} 17190$, de 30 de outubro de 2012. Jornal $Z H$, ano 48, $\mathrm{n}^{\circ} 17191$, de 31 de outubro de 2012. Jornal $Z H$, ano 48, $\mathrm{n}^{\circ} 17193$, de 02 de novembro de 2012. Jornal $Z H$, ano 48, n ${ }^{\circ} 17196$, de 05 de novembro de 2012. Jornal $Z H$, ano 48, $\mathrm{n}^{\circ} 17197$, de 06 de novembro de 2012. Jornal $Z H$, ano 49, $\mathrm{n}^{\circ} 17563$, de 09 de novembro de 2013.

Recebido em: 20/01/2022

Aprovado em: 21/02/2022

Publicado em: 25/02/2022 